\title{
Amblyomma triste (Acari: Ixodidae): New North American Collection Records, Including the First From the United States
}

\author{
JAMES W. MERTINS, ${ }^{1,2}$ ARNOLD S. MOORHOUSE, ${ }^{3}$ JEFFERY T. ALFRED,${ }^{1}$ \\ AND H. JOEL HUTCHESON ${ }^{1}$
}

J. Med. Entomol. 47(4): 536-542 (2010); DOI: 10.1603/ME09165

\begin{abstract}
New distribution records for the Neotropical tick, Amblyomma triste Koch, are identified from 27 specimens in 18 separate collections. These collections originated from six now recognized geographical foci in two states in the United States (Cochise and Santa Cruz Counties, Arizona, and Brewster and Jeff Davis Counties, Texas) and from import cattle, Bos taurus L., presented for entry at the United States border and originating in three Mexican states (Coahuila, Durango, and Sonora). For at least $67 \mathrm{yr}, A$. triste has existed in some areas of the United States as a cryptic species, and specimens there have been confused with and identified as Gulf Coast ticks, Amblyomma maculatum Koch, even by noted tick specialists. Most of the records reported in this study were from reidentified, archived specimens of putative A. maculatum.
\end{abstract}

KEY WORDS Amblyomma maculatum, tick distribution, biogeography, Arizona

Amblyomma triste Koch was originally described from Montevideo, Uruguay (Koch 1844), and it since has mostly been treated as a Neotropical species (Evans et al. 2000, Guglielmone et al. 2003). Exceptions were Graham et al. (1975) and Woodham et al. (1983), both of whom alluded to the widespread existence of $A$. triste in Mexico, including some Nearctic areas, but did not cite voucher specimens, specific localities, or other supporting collection data.

A major confounding issue in the historical recognition of the true geographical occurrence of A. triste was the treatment of the taxon (along with Amblyomma tigrinum Koch) as synonymous with Amblyomma maculatum by Neumann (1899) and subsequent authors (e.g., Robinson 1926, Cooley and Kohls 1944). Later, Kohls (1956) finally clarified the distinct status of $A$. triste, but during the intervening $57 \mathrm{yr}$ (1899-1956), published information about A. triste is confused and all but subsumed within that referring to A. maculatum. During the next $50 \mathrm{yr}$, at least within the Neotropical Region, A. triste mostly was recognized as a distinct entity, but it was little studied, except for new collection, host, and distribution records (Guerrero 1996; Szabó et al. 2003; Venzal et al. 2003a, b). Despite Kohls (1956), a few authors continued passively (Hoffmann 1962, Conti-Diaz et al. 1990, Hoff-

\footnotetext{
${ }^{1}$ United States Department of Agriculture, Animal and Plant Health Inspection Service, Veterinary Services, National Veterinary Services Laboratories, 1800 Dayton Avenue, Ames, IA 50010.

${ }^{2}$ Corresponding author: United States Department of Agriculture, Animal and Plant Health Inspection Service, Veterinary Services, National Veterinary Services Laboratories, 1800 Dayton Avenue, Ames, IA 50010 (e-mail: James.W.Mertins@aphis.usda.gov).

${ }^{3}$ United States Department of Agriculture, Animal and Plant Health Inspection Service, Veterinary Services, United States Customs Building, Room 204, Pan American Avenue, Douglas, AZ 85607.
}

man and López-Campos 2000) or intentionally (Mendoza-Uribe and Chávez-Chorocco 2004) to treat A. triste as a part of A. maculatum.

In more recent years, some detailed studies of Neotropical A. triste have appeared (Labruna et al. 2003, Oliveira et al. 2006), including its status as a major vector of a spotted-fever rickettsial agent to humans in Argentina, Brazil, and Uruguay (Venzal et al. 2004, 2008; Pacheco et al. 2006; Silveira et al. 2007; Nava et al. 2008). Evidently, the proven Neotropical distribution of A. triste covers only portions of eight countries in northern and central South America (Guglielmone et al. 2003, Estrada-Peña et al. 2005, Nava et al. 2007), although Graham et al. (1975) suggest without documentation that the range extends into Central America. Only recently have Guzman-Cornejo et al. (2006) been able to document the presence of this tick in Nearctic areas of Mexico.

For $>45$ yr, the United States Department of Agriculture (USDA) has conducted a continuous National Tick Surveillance Program (NTSP) designed to collect and identify ticks within the United States and its territories. The origins of this program trace to the USDA's early efforts to eradicate cattle fever ticks, Rhipicephalus (Boophilus) spp., from the country (Cotton 1908, USDA 1962). That emphasis on fever ticks continues to this day along the Texas-Mexico border (Hillman and Ugstad 2008). However, the NTSP also seeks to intercept as early as possible any unusual or exotic ticks that might otherwise invade undetected into new domestic geographic areas and thereby present potential new threats to the health of American livestock, wildlife, or the human population (USDA 1963). 
In September 2004, while processing routine tick collections from Mexican cattle, Bos taurus L., presented at Texas ports for entry into the United States, one of us (J.W.M.) encountered and identified a single male A. triste in one sample tube. We notified the appropriate concerned USDA, Animal and Plant Health Inspection Service (APHIS) officials of the identification, and the interception was publicized internally to personnel along the international border to assure a high level of vigilance for any more unusual ticks on presented livestock. This interception of $A$. triste occurred 2 yr before Guzman-Cornejo et al. (2006) authenticated the presence of A. triste in Mexico, and at the time, the only known, confirmed previous collections for $A$. triste were from northern and central South America. Given these cited circumstances and the known similarities (Guglielmone et al. 2003) between A. triste and A. maculatum, we hypothesized that other, earlier collections of A. triste were sent to the NTSP at the National Veterinary Services Laboratories (NVSL) from areas within Mexico or along the United States-Mexico border, but the ticks in the samples were misidentified as A. maculatum.

We report in this study the results of testing that hypothesis, and we document and discuss the implications of multiple new North American distribution records found for A. triste, including the first collections of this tick from the United States.

\section{Materials and Methods}

We sought out all extant NVSL paper and electronic documents, records, and reports that cited collections of A. maculatum in the geographic areas of concern. The initial pool of records from all areas and all sources represented over 7,000 collections, but we concentrated our attention on only those from South Texas, West Texas, and areas to their west. We assessed each record for veracity in the best available way, including, if possible, re-examination under the dissecting microscope of actual tick specimens still in our holdings. All species reidentifications were based upon keys, descriptions, and illustrations in recent treatments of the A. maculatum tick group by Estrada-Peña et al. (2002, 2005), supplemented by comparison with bona fide A. maculatum reference specimens from Florida and eastern Texas. We were able to morphologically distinguish A. triste adults from those of A. maculatum based upon the presence of only one apical spine on each metatarsus of legs II, III, and IV; the more extensive scutal ornamentation and more prominent scutal punctation; and in males, on the size and shape of the spiracular plates and their dorsal processes.

In addition to reassessment of older specimens, we carefully examined new submissions to our laboratory of putative A. maculatum specimens from the United States-Mexican border region. Finally, we reviewed and pursued the published literature on A. maculatum in North America, especially with respect to collections made in geographic localities deemed unusual for that species. Where available, we borrowed voucher specimens of suspect reports for re-evaluation.

Except as noted, voucher specimens for the collection records we discuss in this report are retained in the NVSL parasitology reference collection. Additional voucher specimens, as noted, are retained in other permanent North American collections.

\section{Results}

Altogether from all of our sources, we verified 18 new collections comprising 27 specimens of A. triste from North American localities (Table 1). After our first encounter with a Mexican A. triste in September 2004, we were able to locate, identify, and confirm 10 other collections in our NVSL records and holdings, based upon re-examination of archival specimens. We found a larger number of suspect/putative A. maculatum collections in our records and in published accounts, but we could neither verify nor refute the true identities of those ticks because they are no longer represented by actual stored specimens. We also identified other, recently collected A. triste specimens from import cattle in submissions from APHIS livestock inspectors at the Mexican border. We found additional specimens in recent, routine domestic tick submissions, and more archived specimens at other institutions as a result of our literature search.

The NVSL parasitology reference collection served as the richest and most immediate source for new $A$. triste records. It contained nine historical (i.e., from $1963,1992,1997,2000$ ) accessions (Table 1) of putative A. maculatum ticks from anomalous localities in southeastern Arizona and West Texas that drew our immediate reassessment. Collection sites for these ticks formed two tight, but disjunct geographic clusters, and we reidentified all of the specimens as $A$. triste. The 1963 collection from a yearling cow lacks a specific locality, but it is from the same county (Cochise County, Arizona) as six other, later-identified collections, all centered in the San Pedro River Valley, from songbirds being banded, a pet dog, Canis lupus familiaris L., and a road-killed mule deer, Odocoileus hemionus hemionus (Rafinesque). The 1963 tick represents the current oldest known extant $A$. triste specimen in our possession.

The nymphal ticks from bird hosts present a less definitive facies than do the adults, and thus, we cannot independently verify their identity as A. triste. Although Estrada-Peña et al. (2005) presented an illustrated key for distinguishing nymphal A. triste from A. maculatum nymphs, we find it is inadequate for this purpose. Indeed, these authors also recognized and discussed the subjective nature of the specified differences noted in the key and the associated difficulty in using them in practice. We were unable to unequivocally identify our Arizona nymphs as A. triste using this key. In fact, statements in this key do not conform to accompanying illustrations, and descriptive information for A. triste nymphs in Estrada-Peña et al. (2005) disagrees with information in their original description (Estrada-Peña et al. 2002), which itself is 

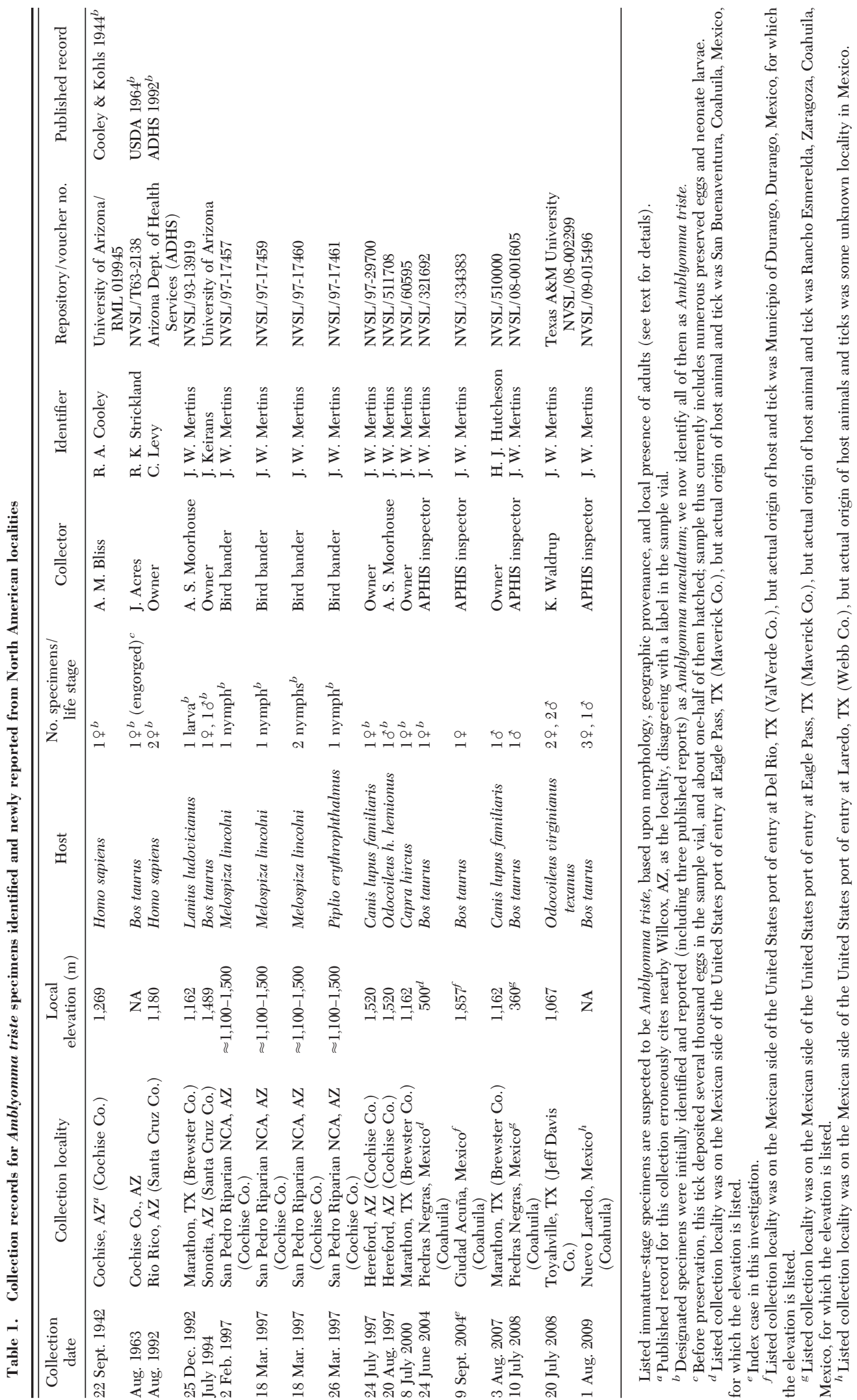
internally inconsistent. Our comparison of our five nymphal specimens with known A. maculatum nymphs from Florida and Texas also did not find any reliable differences between the two species. Nevertheless, we are convinced that coincidence of these immature Amblyomma ticks with known adult A. triste in the San Pedro River Valley, far from the range of $A$. maculatum, strongly supports the notion that they are A. triste, as well.

The second focus for anomalous archived NVSL collections of putative A. maculatum ticks centered on Marathon, in Brewster County, Texas (Table 1). It includes a single tick larva taken by one of us (A.S.M.) in 1992 from a road-killed loggerhead shrike, Lanius ludovicianus L., near Marathon, and a female tick taken in 2000 from a domestic goat, Capra hircus L., in Marathon. We now reidentify both ticks as A. triste. In 2007, the owner of the goat collected another A. triste from a pet dog (Table 1). Larval A. triste are inseparable morphologically from those of A. maculatum (Estrada-Peña et al. 2005), but verified later collections of adult A. triste in the immediate vicinity provide strong supporting evidence that our larval tick is not A. maculatum, but instead A. triste.

Support for another Texas focus of A. triste occurrence comes from a 2008 collection of five adult ticks on two Texas white-tailed deer, Odocoileus virginianus texanus (Mearns), in the Davis Mountains of Jeff Davis County (Table 1). We routinely received and identified two separate subsamples of ticks from this collection as A. triste.

Our examination of records for Amblyomma ticks collected from Mexican livestock presented for entry at the United States border yielded additional specimens and four records of A. triste (Table 1). The first of these was correctly recognized in September 2004 upon its arrival at NVSL, and in epidemiological terms, it was the index case; i.e., it was the tick that alerted us to the possible presence of A. triste in Mexico and set us to looking for more evidence and information.

We were able to ascertain $\approx 60$ additional NVSL records of A. maculatum identified from Mexican livestock inspected at United States border ports of entry between 1962 and 2009. From still-extant associated specimens, we confirmed about half of these determinations, and based upon source localities, most of the rest are probably accurate, as well. However, the 10 most westerly, unvouchered collections remain highly suspect, but unverifiable, as misidentified A. triste. The most suspect of all (USDA 1985, accession 83-32843) originated in Múzquiz, Coahuila, the same Mexican municipio with documented A. triste specimens in the Mexican Colección Nacional de Ácaros (Guzman-Cornejo et al. 2006).

Likewise, we re-examined a large number of extant records and/or specimens originally identified as A. maculatum and originating from Arizona, California, or multiple localities in 17 South Texas counties. We found no suspect older records of A. maculatum from New Mexico. Still-extant specimens confirmed over 100 of these identifications, but hundreds of others could not be so studied, including four from Arizona and one from California that are highly suspect as A. triste misidentifications.

Finally, we reviewed available published distribution records for A. maculatum, looking for any that seemed suspicious in light of our new understanding of the possibly confused Nearctic occurrence of $A$. triste. This effort yielded three especially suggestive records that we pursued.

The first two records date back over 100 and over 65 yr, respectively. Cooley and Kohls (1944) report six published and unpublished collection records for $A$. maculatum in localities outside the then known limits of its distribution. Only two of these raised our interest. The Tulare County, California, record probably dates to the 1800s and has been repeated subsequently by numerous authors, but we could not trace it to an actual extant specimen. The second record designates a 1942 collection of A. maculatum from Arizona. We traced this specimen to the arthropod collection at the University of Arizona, whence we borrowed and examined it (Table 1). It is, in fact, a damaged, flat female A. triste. Labels in the specimen vial provide the actual collection locality was Cochise, Arizona, and the identifier was R. A. Cooley. This specimen represents the oldest known collection of A. triste in the United States and the first known from North America and the Nearctic Region. It also establishes a collection locality in the northern part of Cochise County, separate from the much later southern Cochise County collections near Hereford.

The last published record we found (ADHS 1992) reported adult A. maculatum ticks collected from a human hiker walking his dog in a canyon near Rio Rico, Santa Cruz County, Arizona (Table 1). We borrowed the specimens from the Department of Health Services, in Phoenix, Arizona; the two flat females are, in fact, A. triste. This record establishes a second focus of occurrence for A. triste in a second Arizona county, and it represents the geographically westernmost collection of this tick in the United States. By what is probably not an accident, one of the unvalidated NVSL collection records (USDA 1988, accession 8743671) for A. maculatum in Arizona is for a male tick collected from the ear of a dog on 24 August 1987 in Rio Rico. Based upon the just-discussed, nearly identical collection record $5 \mathrm{yr}$ later, we think that the discarded 1987 tick was A. triste, as well. The University of Arizona arthropod collection also loaned us an unpublished 1994 collection of putative A. maculatum from northern Santa Cruz County, Arizona (Table 1), now reidentified as A. triste.

\section{Discussion}

A. triste was originally described as and long has been known as a Neotropical species (Koch 1844, Guglielmone et al. 2003). Despite vague, unverifiable reports of its presence in Nearctic areas of Mexico (Graham et al. 1975, Woodham et al. 1983), actual substantiating specimens were located only recently by Guzman-Cornejo et al. (2006), who cited three 
newly recognized, but 30-yr-old archival collections in the Mexican Colección Nacional de Ácaros.

To these three cited and proven Mexican collection records (i.e., one in Yécora, Sonora, and two others in a single locality, Las Pilas, Múzquiz, Coahuila), we now add three new locality records (Table 1 ). Thus, at present, we have five specific, documented, and vouchered collection localities in three Mexican states (i.e., Coahuila, Durango, and Sonora), and all of the sites lie within the Nearctic Region, the Mexican Highlands, and either in or near the Chihuahuan Desert, a situation not unlike that in the United States.

Our review of archived NVSL records and case reports and of older literature for A. maculatum in the Nearctic Region suggests that A. triste has existed there long-term-our oldest specimen dates from 1942-in a sort of cryptic species limbo, i.e., as a misidentified (Bickford et al. 2007), uncertain, and neglected species. We and our predecessors at NVSL misidentified specimens for more than four decades, and experts like Keirans and Cooley (Table 1) also did so in the same and earlier years. Among recent authors, neither Hoffmann and López-Campos (2000) nor Guglielmone et al. (2003) recognized the presence of A triste in Mexico. In the United States, an extensive 4-yr ectoparasite survey on mammals in a now known infested locality, Brewster County, Texas, found 11 species of ticks, but did not identify any A. triste or A. maculatum (Richerson et al. 1992).

Considering only the validated North American collection records for A. triste to date, we observe that all of them come from localities west of the 100th meridian, the traditional, symbolic boundary between the North American East and West (Powell 1879). Voluminous NVSL records for verified collections of A. maculatum in Texas show that its occurrence west of $100^{\circ}$ is very rare. The 100th meridian roughly represents a continental transition zone between eastern and western landforms, climates, ecoregions, water resources, agriculture, floras, and faunas (Hunt 1974). Furthermore, known collection sites for North American A. triste lie in or on the fringes of the Chihuahuan Desert and in the Mexican Highlands section of the Basin and Range Province in both the United States and Mexico (Hunt 1974, Morone 2005). This is generally high country, with some peaks to over $3,000 \mathrm{~m}$, but mountains make up only about one-third of the area, and the rest is occupied by high valleys. Elevations of the known specific collection sites for A. triste are mostly low for the region (Table 1), and probably all are in mountain valleys (Richerson et al. 1992). Average annual precipitation in this region is between 250 and $500 \mathrm{~mm}$, and native vegetation is typically xerophilic.

Collectively, the information and observations we present in this report suggest to us that some unresolved issues remain within the A. maculatum species group, especially with respect to the status of A. triste. For example, known collection records to date show no presence of this tick in Central America, leaving two disjunct populations in the Nearctic and Neotropical Regions, respectively. The Nearctic population is represented in collections by very few specimens ( 27 confirmed by us), and no biological or ecological studies have been done on it. Admittedly, scant collection data from the few extant specimens suggest that Nearctic A. triste inhabit moderately warm, arid highland habitats, with adults feeding on medium to large size mammals and immature stages on birds. However, studies of A. triste in South America (Venzal and Fregueiro 1999, Labruna et al. 2003, Szabó et al. 2003, Venzal et al. 2003a, Nava et al. 2008) found that those ticks favor warm, moist (even marshy) lowland habitats, with adults occurring on a similar range of hosts, but immatures mostly on rodents and marsupials (Venzal et al. 2008, Nava et al. 2008). Furthermore, although Estrada-Peña et al. (2005) were able to discern morphological differences between nymphal $A$. maculatum and South American A. triste nymphs, we could not do so for North American specimens. When more Nearctic specimens of A. triste become available, further study and comparison may find that they differ morphologically and specifically from nominate Neotropical A. triste. Indeed, Szabó et al. (2007) and Venzal et al. (2008) observed and discussed differences between A. triste populations in various parts of South America, suggesting that taxonomic diversity in this taxon may exist even within that region. GuzmanCornejo et al. (2006) noted a morphological discrepancy in the prominence of the tubercles on the festoons of Mexican versus Uruguayan specimens of A. triste.

The actual distribution and abundance of A. triste in North America also remain to be determined. Only two known United States species of Amblyomma occur exclusively west of the 100th meridian, Amblyomma elaphense (Price) and A. triste. The range of $A$. elaphense is the more limited (Degenhardt and Degenhardt 1965), but it largely coincides with the northeastern part of the A. triste distribution in the Chihuahuan Desert. All other present-day Amblyomma ticks in the United States are restricted to more humid habitats east of the 100th meridian and seem unable to survive in this arid region. A. elaphense is found nowhere else outside the Chihuahuan Desert; in nature, it seems host specific to the Trans-Pecos rat snake, Bogertophis subocularis (Brown), and limited in occurrence to the range of this host (Degenhardt and Degenhardt 1965). As a consequence, it is uncommonly collected, little studied, and was not discovered until 1956 (Price 1958). Nevertheless, this close hostparasite relationship might suggest a longtime association and occurrence of the tick in the area. According to Kaufman (1972) and Klompen et al. (2002), A. elaphense is a primitive member of its genus, and Nava et al. (2009) state its origins are Laurasian. This information implies that its lineage may have been present in what is now North America for at least 60 million yr, although the lampropeltine lineage of its current specific snake host did not enter North America until $\approx 25$-30 million yr ago (Burbrink and Lawson 2007). Other ancient American Amblyomma spp. ticks are known from Dominican amber dating to 30-40 million yr ago (Lane and Poinar 1986, Keirans et al. 
2002), so there is no doubt of the long-term occurrence of the Amblyomma lineage in the Americas. A. triste has verifiably been present, but unrecognized, in the United States for at least $68 \mathrm{yr}$, perhaps for $>110$ $\mathrm{yr}$, and probably for much longer. We think that current North American populations of A. triste may even be a remnant of its continual presence in the North American West since prehistoric times, and perhaps both A. elaphense and A. triste are relict species of what once may have been a more diverse Amblyomma fauna in this area.

What little we know of North American A. triste suggests that its hosts are much more diverse (e.g., deer, goats, cattle, humans, or dogs for adults, and birds for subadults) and its geographic range is somewhat larger than those, respectively, of A. elaphense. Its lineage has been present here for a long time, as well, but it also is uncommonly collected and little studied. The Chihuahuan Desert is sparsely populated by humans, which probably largely accounts for our failure to recognize and study both of these ticks sooner and more thoroughly. Available evidence suggests to us that, within this area, A. triste may not be a common tick, and perhaps it exists only at low densities in small, local pockets of suitable habitat. We expect that this first report of A. triste in the United States will stimulate other workers to seek out more specimens and information on it in the future and clarify its status with respect to its Neotropical counterparts.

\section{Acknowledgments}

We thank the following people for their assistance in search for or acquisition of specimens or literature used in this study: Lorenza Beati (United States National Tick Collection), Jonathan Coddington (National Museum of Natural History, Smithsonian Institution), Neal Evenhius (Natural Sciences Department, Bishop Museum), Art Harris (Centennial Museum, University of Texas, El Paso), Craig Levy (Vector-Borne and Zoonotic Diseases Program Arthropod Collection, Arizona Department of Health), Gary Racel (USDA, APHIS), Pete Teel (Department of Entomology, Texas A\&M University), Carl Olson (Department of Entomology, University of Arizona), Janice Eifling (USDA, National Centers for Animal Health), Ken Waldrup (Texas Department of State Health Services), Jack Whetstone (San Pedro Riparian National Conservation Area, United States Bureau of Land Management), and the APHIS "tick rider" force and border inspectors.

\section{References Cited}

[ADHS] Arizona Department of Health Services. 1992. Gulf Coast ticks identified in Santa Cruz County. VectorBorne Zoonotic Diseases (News), Arizona Department of Health Services, Division of Disease Prevention, Phoenix, AZ.

Bickford, D., D. J. Lohman, N. S. Sohdi, P.K.L. Ng, R. Meier, K. Winker, K. K. Ingram, and I. Das. 2007. Cryptic species as a window on diversity and conservation. Trends Ecol. Evol. 22: 148-155.

Burbrink, F. T., and R. Lawson. 2007. How and when did Old World rat snakes disperse into the New World? Mol. Phylogenet. Evol. 43: 173-189.
Conti-Diaz, I. A., I. Rubio, R. E. Somma Moreira, and G. Pérez Bormida. 1990. Lymphatic cutaneous rickettsioses caused by Rickettsia conorii in Uruguay. Rev. Inst. Med. Trop. Sao Paulo 32: 313-318.

Cooley, R. A., and G. M. Kohls. 1944. The genus Amblyomma (Ixodidae) in the United States. J. Parasitol. 30: $77-111$.

Cotton, E. C. 1908. Tick eradication: the life history and habits of the North American fever tick with special reference to eradication. Tenn. Agric. Exp. Stn. Bull. 81: 53-71.

de Oliveira, P. R., M. I. Camargo Mathias, and G. H. Bechara. 2006. Amblyomma triste (Koch, 1844) (Acari: Ixodidae): morphological description of the ovary and of vitellogenesis. Exp. Parasitol. 113: 179-185.

Degenhardt, W. G., and P. B. Degenhardt. 1965. The hostparasite relationship between Elaphe subocularis (Reptilia: Colubridae) and Aponomma elaphensis (Acarina: Ixodidae). Southwest. Nat. 10: 167-178.

Estrada-Peña, A. J., M. Venzal, and A. A. Guglielmone. 2002. Amblyomma dubiatum Neumann: description of nymph and redescription of adults, together with the description of the immature stages of A. triste Koch. Acarologia 42: 323-333.

Estrada-Peña, A. J., M. Venzal, A. J. Mangold, M. M. Cafrune, and A. A. Guglielmone. 2005. The Amblyomma maculatum Koch, 1844 (Acari: Ixodidae: Amblyomminae) tick group: diagnostic characters, description of the larva of $A$. parvitarsum Neumann, 1901, 16S rDNA sequences, distribution and hosts. Syst. Parasitol. 60: 99-112.

Evans, D. E., J. R. Martins, and A. A. Guglielmone. 2000. A review of the ticks (Acari: Ixodida) of Brazil, their hosts and geographical distribution. 1. The State of Rio Grande du Sol, southern Brazil. Mem. Inst. Oswaldo Cruz 95: 453-470.

Graham, O. H., W. J. Gladney, and L. G. Beltran. 1975. Comparación de la distribución e importancia económica de la garrapata Amblyomma maculata Koch (Acarina: Ixodidae), en México y los Estados Unidos. Folia Entomol. Mex. 33: 66-67.

Guerrero, R. 1996. Las garrapatas de Venezuela (Acarina: Ixodoidea): listado de especies y claves para su identificación. Bol. Direc. Malariol. Saneam. Amb. 36: 1-24.

Guglielmone, A. A., A. Estrada-Peña, J. E. Keirans, and R. G. Robbins. 2003. Ticks (Acari: Ixodidae) of the Neotropical Zoogeographic Region. Special Publication, International Consortium on Ticks and Tick-Borne Diseases, Atalanta, Houten, The Netherlands.

Guzman-Cornejo, C., T. M. Pérez, S. Nava, and A. A. Guglielmone. 2006. Confirmation of the presence of Amblyomma triste Koch, 1844 (Acari: Ixodidae) in Mexico. Syst. Appl. Acarol. 11: 47-50.

Hillman, B., and P. Ugstad. 2008. Update on the Cattle Fever Tick Eradication Program, pp. 564-567. In Proceedings, 111th Annual Meeting of the United States Animal Health Association, 18-24 October 2007, Reno, NV. U.S. Animal Health Association, St. Joseph, MO.

Hoffmann, A. 1962. Monografía de los Ixodoidea en México: I parte. Rev. Soc. Mex. Hist. Nat. 23: 191-307.

Hoffmann, A., and G. López-Campos. 2000. Biodiversidad de los ácaros en México. Comisión Nacional para el Conocimiento y Uso de la Biodiversidad, México D.F., México.

Hunt, C. B. 1974. Natural regions of the United States and Canada. W. H. Freeman and Co., San Francisco, CA.

Kaufman, T. S. 1972. A revision of the genus Aponomma Neumann, 1899 (Acarina: Ixodidae). Ph.D. dissertation, University of Maryland, College Park. 
Keirans, J. E., R. S. Lane, and R. Cauble. 2002. A series of larval Amblyomma species (Acari: Ixodidae) from amber deposits in the Dominican Republic. Int. J. Acarol. 28: 61-66.

Klompen, H., S. J. Dobson, and S. C. Barker. 2002. A new subfamily, Bothriocrotoninae n. subfam., for the genus Bothriocroton Keirans, King \& Sharrad, 1994 status amend. (Ixodida: Ixodidae), and the synonymy of Aponomma Neumann, 1899 with Amblyomma Koch, 1844. Syst. Parasitol. 53: 101-107.

Koch, C. L. 1844. Systematische Übersicht über die Ordnung der Zecken. Arch. Naturgesch. 10: 217-239.

Kohls, G. M. 1956. Concerning the identity of Amblyomma maculatum, A. tigrinum, A. triste, and A. ovatum of Koch, 1844 (Acarina, Ixodidae). Proc. Entomol. Soc. Wash. 58: 143-147.

Labruna, M. B., E.Y.M. Fugisaki, A. Pinter, J.M.B. Duarte, and M.P.J. Szabó. 2003. Life cycle and host specificity of Amblyomma triste (Acari: Ixodidae) under laboratory conditions. Exp. Appl. Acarol. 30: 305-316.

Lane, R. S., and G. O. Poinar, Jr. 1986. First fossil tick (Acari: Ixodidae) in New World amber. Int. J. Acarol. 12: 75-78.

Mendoza-Uribe, L., and J. Chávez-Chorocco. 2004. Ampliación geográfica de siete especies de Amblyomma (Acari: Ixodidae) y primer reporte de A. oblongoguttatum Koch, 1844 para Perú. Rev. Peruvana Entomol. 44: 69-72.

Morone, J. J. 2005. Hacia una síntesis biogeográfica de México. Rev. Mex. Biodiv. 76: 207-252.

Nava, S., M. Lareschi, C. Rebollo, C. Benítez Usher, L. Beati, R. G. Robbins, L. A. Durden, A. J. Mangold, and A. A. Guglielmone. 2007. The ticks (Acari: Ixodida: Argasidae, Ixodidae) of Paraguay. Ann. Trop. Med. Parasitol. 101: 255-270.

Nava, S., Y. Elshenawy, M. E. Eremeeva, J. W. Sumner, M. Mastropaolo, and C. D. Paddock. 2008. Rickettsia parkeri in Argentina. Emerg. Infect. Dis. 14: 1894-1897.

Nava, S., A. A. Guglielmone, and A. J. Mangold. 2009. An overview of systematics and evolution of ticks. Front. Biosci. 14: 2857-2877.

Neumann, L. G. 1899. Révision de la famille des Ixodidés $\left(3^{\mathrm{e}}\right.$ mémoire). Mém. Soc. Zool. France 12: 107-294.

Pacheco, R. C., J. M. Venzal, L. J. Richtzenhain, and M. B. Labruna. 2006. Rickettsia parkeri in Uruguay. Emerg. Infect. Dis. 12: 1804-1805.

Powell, J. W. 1879. Report on the lands of the Arid Region of the United States, with a more detailed account of the lands of Utah: with maps, 2nd ed. U.S. Government Printing Office, Washington, DC.

Price, M. A. 1958. A new species of tick from the TransPecos Region of Texas. J. Parasitol. 44: 649-651.

Richerson, J. V., J. F. Scudday, and S. P. Tabor. 1992. An ectoparasite survey of mammals in Brewster County, Texas, 1982-1985. Southwest. Entomol. 17: 7-15.

Robinson, L. E. 1926. The genus Amblyomma, pp. i-xii and 1-302 (part IV). In G.H.F. Nuttall, C. Warburton, and L. E. Robinson (eds.), Ticks: a monograph of the Ixodoidea. Cambridge University Press, London, United Kingdom.

Silveira, I., R. C. Pacheco, M.P.J. Szabó, H.G.C. Ramos, and M. B. Labruna. 2007. Rickettsia parkeri in Brazil. Emerg. Infect. Dis. 13: 1111-1113.
Szabó, M.P.J., M. B. Labruna, M. C. Pereira, and J.M.B. Duarte. 2003. Ticks (Acari: Ixodidae) on wild marshdeer (Blastocerus dichotomus) from southeast Brazil: infestations before and after habitat loss. J. Med. Entomol. 40: $268-274$.

Szabó, M.P.J., M. B. Castro, H.G.C. Ramos, M. V. Garcia, K. C. Castagnolli, A. Pinter, V. A. Veronez, G. M. Magalhães, J.M.B. Duarte, and M. B. Labruna. 2007. Species diversity and seasonality of free-living ticks (Acari: Ixodidae) in the natural habitat of wild marsh deer (Blastocerus dichotomus) in southeastern Brazil. Vet. Parasitol. 143: $147-154$.

[USDA] U.S. Department of Agriculture. 1962. Report of cooperative cattle fever tick eradication activities fiscal year 1962. Animal Disease Eradication Division, Agriculture Research Service, Hyattsville, MD.

[USDA] U.S. Department of Agriculture. 1963. Report of cooperative tick eradication activities fiscal year 1963 . Animal Disease Eradication Division, Agriculture Research Service, Hyattsville, MD.

[USDA] U.S. Department of Agriculture. 1964. Report of cooperative cattle fever tick eradication activities fiscal year 1964. Animal Disease Eradication Division, Agriculture Research Service, Hyattsville, MD.

[USDA] U.S. Department of Agriculture. 1985. National Tick Surveillance Program calendar year 1983. Veterinary Services, Animal and Plant Health Inspection Service. APHIS February: 91-39.

[USDA] U.S. Department of Agriculture. 1988. National Tick Surveillance Program calendar year 1987. Veterinary Services, Animal and Plant Health Inspection Service. APHIS August: 91-39.

Venzal, J. M., and G. Fregueiro. 1999. Ixodidos parasitos de marsupiales (Didelphimorphia: Didelphidae) y roedores (Rodentia: Muridae) de la fauna Uruguaya. Jornada de Clínica. Reproducción y Consevación de Animales Silvestres. Facultad de Veterinaria, Montevideo, Uruguay.

Venzal, J. M., O. Castro, P. A. Cabrera, C. G. Souza, and A. A. Guglielmone. 2003a. Las garrapatas de Uruguay: especies, hospedadores, distribución e importancia sanitaria. Veterinaria (Montevideo) 38: 17-28.

Venzal, J. M., E. M. González, D. Capellino, A. Estrada-Peña, and A. A. Guglielmone. 2003b. First record of Amblyomma triste Koch, 1844 (Acari: Ixodidae) and new records of Ornithodoros mimon Kohls, Clifford \& Jones, 1969 (Acari: Argasidae) from Neotropical bats. Syst. Appl. Acarol. 8: 93-96.

Venzal, J. M., A. Portillo, A. Estrada-Peña, O. Castro, P. A. Cabrera, and J. A. Oteo. 2004. Rickettsia parkeri in Amblyomma triste from Uruguay. Emerg. Infect. Dis. 10: 1493-1495.

Venzal, J. M., A. Estrada-Peña, O. Castro, F. G. de Souza, M. L. Félix, S. Nava, and A. A. Guglielmone. 2008. Amblyomma triste Koch, 1844 (Acari: Ixodidae): hosts and seasonality of the vector of Rickettsia parkeri in Uruguay. Vet. Parasitol. 155: 104-109.

Woodham, C. B., A. González Origel, A. López León, and T. Guereña Morales. 1983. Progress in the eradication of Boophilus ticks in Mexico 1960-80. World Anim. Rev. 48: $18-24$.

Received 26 June 2009; accepted 19 March 2010 